\title{
El Geoportal como vía de acceso a información cartográfica de pronta respuesta. Caso de estudio del sismo de Ecuador en abril del 2016
}

\author{
Martha Villagómez Orozco* \\ Álvaro Dávila Granda* \\ Rosa Cuesta Molestina*
}

Recibido el 16 de enero de 2017; aceptado el 13 de junio de 2017

\begin{abstract}
Ecuador is one of the countries where natural hazards are a real problem. This is because of some aspects linked of human settlements which are located at risk areas, which contain several natural hazards some of them are catastrophic at regional level, but also at the national level.

About the cartographic technical aspect, these circumstances raise the need to solve two problems at the same time: the availability of useful information in the shortest possible time and to transmit immediately the data to the different users who works with the management of rehabilitation and planning the geographical space affected. The first is related to the ability to generate quick response map information and the second one, with access to information technologies through SDI and Geoportal. In order to disseminate the actions taken within an Ecuadorian public institution, this article presents what actions and results were achieved in support of risk management in the earthquake on April 16, 2016; the earthquake had devastating effects in towns of the center-north coast of Ecuador.

The action plan developed and implemented for the first time in Ecuador established a starting point. In the future this will allow to implement the improvements in other similar cases and to be a reference for other places where geoportals are implemented for the availability of cartographic information and the attention in case of natural disasters. In the case of Ecuador, the availability of timely and easily

* Instituto Geográfico Militar (IGM), Seniergues E4-676 y Gral. Telmo Paz y Miño, El Dorado, Quito, Ecuador, correos electrónicos: martha.villagomez@mail.igm.gob.ec, alvaro.davila@mail.igm.gob.ec, rosa.cuesta@mail.igm.gob.ec
\end{abstract}


accessible cartographic information was a matter of great importance for the emergency response in April 2016.

Key words: Earthquake, Geoportal, Quick response mapping, SDI, Geographic information technologies.

\section{Resumen}

La República de Ecuador es uno de los países donde los desastres naturales constituyen un problema latente debido a factores ligados con la localización de asentamientos humanos en zonas de riesgo. El país se enfrenta además a una amplia diversidad de peligros naturales, que en algunas ocasiones han tenido efectos catastróficos a nivel regional, e incluso a nivel nacional. Estas contingencias, en el aspecto técnico geográfico-cartográfico, plantean la necesidad de resolver paralelamente dos problemas: por un lado, la generación y disponibilidad de información útil en el menor tiempo posible; y por otro, tener los mecanismos idóneos para la transmisión inmediata de los datos hacia los diferentes usuarios encargados de la rehabilitación y planificación del espacio geográfico afectado. El primero, se relaciona con la capacidad para generar información de pronta respuesta y el segundo, con el acceso a la información a través de los Geoportales. En el artículo que se presenta, se exponen las acciones y resultados que se alcanzaron en apoyo a la gestión de riesgos frente al terremoto sucedido el 16 de abril de 2016, que tuvo efectos devastadores, principalmente en ciertos poblados de la costa centro-norte ecuatoriana.

Se considera que, el plan de acción desarrollado y aplicado por primera vez en Ecuador estableció un punto de partida que permitirá en lo futuro implementar las mejoras del caso producto de la experiencia adquirida, y de esta manera ser un referente para ser aprovechado en otros lugares donde se implementen geoportales con aplicaciones muy puntuales referidas a la disponibilidad de información cartográfica para la atención en casos de desastres naturales. En el caso de Ecuador la disponibilidad de información cartográfica oportuna y de fácil acceso fue una cuestión de gran importancia para la atención de la emergencia acaecida en abril de 2016.

Palabras clave: terremoto, Geoportal, Cartografía de pronta respuesta, IDE, Tecnologías de información geográfica.

\section{Resumo}

A República do Equador é um dos países onde os desastres naturais constituem um problema latente devido a fatores ligados a localização de assentamentos humanos em zonas de risco. O país também enfrenta uma ampla gama de riscos naturais, que em alguns casos tiveram efeitos catastróficos a nível regional e até mesmo a nível 
nacional. Essas contingências técnico-geográficas aumentam a necessidade de resolver dois problemas em paralelo: a geração e disponibilidade de informações úteis no menor tempo possível e, ter os mecanismos adequados para a transmissão imediata dos dados aos diferentes usuários responsáveis pela reabilitação e planejamento do espaço geográfico afetado. O primeiro, se relaciona com a capacidade de gerar informação de pronta resposta e, o segundo, com o acesso a informação através dos Geoportais. No presente artigo, se expõe as ações e resultados que se alcançaram em apoio a gestão de riscos frente ao terremoto ocorrido em 16 de abril de 2016, que teve efeitos devastadores, principalmente em certos povoados da costa centro-norte equatoriana.

Se considera que, o plano de ação desenvolvido e aplicado pela primeira vez no Equador estabeleceu um ponto de partida que permitirá no futuro implementar as melhoras no produto através da experiência adquirida, e desta maneira ser um referencial para ser aproveitado em outros lugares onde se implementem geoportais com aplicações muito pontuais referidas a disponibilidade de informação cartográfica para atenção em casos de desastres naturais. No caso do Equador a disponibilidade de informação cartográfica oportuna e de fácil acesso foi uma questão de grande importância para a atenção da emergência ocorrida em abril de 2016.

Palavras chave: Terremoto, Geoportal, Cartografia de pronta resposta, IDE, Tecnologias de informação geográfica.

\section{Introducción}

El proceso de globalización no solo hace referencia al intercambio económico, sino que también incide en el intercambio de información (Rodríguez et al., 2006; Buzai, 2014). La geoinformación no está al margen de esta revolución de datos, y son varias las condiciones que en la actualidad debe cumplir el intercambio de información. En lo posible, la información debe presentarse en tiempo real, estar actualizada y ser integrable e interoperable (Más et al., 2013). Estos son algunos de los retos que se deben cumplir al planificar la difusión de información geográfica.

La gran cantidad de usuarios de geoinformación, que existen en la actualidad, generan un entorno con características un tanto complejas en el que aparecen diferentes grupos en función de diferentes criterios como: necesidades, restricciones, relaciones internas y externas entre otras. La implementación de las IDE ha solventado en gran medida los problemas de este entorno, facilitando el intercambio de información geográfica cumpliendo con estándares que han permitido el acceso a esta información de todo tipo de usuario en el mundo (Gutiérrez, 2010)

La parte fundamental de las IDE son los datos transformados en información geográfica con sus metadatos disponibles, siendo sus fuentes y formatos variados (Sánchez et al., 2012; Hernández y Flores, 2012) pues puede ser analógica o digital, provenir de diversos sensores para su captura, haber pasado por distintos métodos 
de procesamiento, etc. También son múltiples sus aplicaciones y usos, este es el caso de las fotografías aéreas que para este artículo y en general para la toma de decisión ante desastres naturales (Andrade y Molina, 2016) son de gran importancia y un insumo esencial para la planificación de operaciones de restauración y atención en caso de eventos naturales. Además hay que mencionarlas como una de las fuentes de información más importantes que tienen la propiedad de suministrar una perspectiva completa y tridimensional de los detalles de la superficie terrestre para cualquier escala que se requiera, esto ha permitido su explotación a nivel de estudios temáticos, ya que es de gran utilidad para la captura de información tanto del medio físico urbano como del rural (Olaya, 2014).

Este artículo tiene un doble objetivo:

- Proponer un proceso de creación de "cartografía de pronta respuesta" de espacios geográficos afectados por amenazas naturales, a través del uso de tecnologías de información geográfica.

- Comprobar la utilidad de los geoportales en la transmisión y recepción de información de pronta respuesta, para dar soporte a la toma de decisiones en situaciones de riesgo natural”.

Estos objetivos son presentados de manera práctica en el caso de estudio descrito y que hace referencia al sismo sucedido en abril del 2016 en la costa norte ecuatoriana, considerando los siguientes criterios:

- La generación de productos cartográficos de pronta respuesta como información fundamental.

- La utilización del Geoportal del IGM como herramienta para el acceso, comunicación y uso de la geoinformación.

Las fuentes de información utilizadas corresponden casi en su totalidad al Instituto Geográfico Militar (IGM) de Ecuador, en cuyo geoportal fueron puestas a disposición de los equipos de ayuda. El artículo trata de explicar y difundir en base a esa experiencia, la utilidad de los Geoportales en la transmisión y recepción de información de pronta respuesta.

\section{El problema}

La necesidad de contar con estudios para la planificación e intervención de los espacios geográficos afectados directamente por eventos naturales (Natenzon, 1995), se ha vinculado históricamente a: 
- La escasa información disponible y débil capacidad para generar, en el menor tiempo posible, información útil, de carácter fundamental.

- La ausencia de mecanismos tecnológicos para transmitir y receptar esta información, necesaria para las tareas de evacuación, reconstrucción y ayuda a la población damnificada.

En este sentido, los geoportales constituyen un elemento clave para las Infraestructuras de Datos Espaciales (IDE) porque permiten difundir contenidos y capacidades (Tait, 2005). La importancia de gestionar apropiadamente el geoportal se puso a prueba con el terremoto de abril de 2016, que fue el fenómeno natural más importante, ocurrido en el Ecuador, en los últimos 70 años.

En América Latina, el país de mejor referencia en términos de gestión de desastres naturales es Chile debido al desarrollo de su geoportal nacional, que posee toda la información espacial primaria y temática en función de sus prioridades nacionales, que son el ordenamiento territorial, la educación, la protección social, la salud oportuna, la calidad de vida y los riesgos naturales (Monet, 2014). El Sistema Integrado de Información para Emergencias (SIIE) de Chile es un geoportal orientado a construir mapas digitales ante las diversas amenazas de origen natural como erupciones volcánicas, sismos o tsunamis, entre otras. Esta herramienta fue generada tras el terremoto del 27 de febrero de 2010 en Chile, esa experiencia provocó la necesidad de disponer de información actualizada a fin de visualizar, analizar e identificar las zonas de emergencia y permitir proteger a la población y apoyar en la toma de decisiones a las autoridades competentes (Carrasco, 2017).

Considerando la experiencia de Chile en la atención de emergencias de tipo natural, a fin de dar respuestas a esas carencias en la zona del sismo y tomando en cuenta que la escala de la información requerida debería contemplar el nivel de apreciación de la edificación, el Instituto Geográfico Militar de Ecuador, orientó sus actividades desde hace años atrás a generar información geográfica fundamental que sirviera como base para la cartografía temática y las estadísticas censales que realizaban otras instituciones del Estado. De igual manera se realizaron inversiones económicas y tecnológica a fin de que el Geoportal Institucional sea utilizado como herramienta de transmisión de geoinformación, no solamente la del propio IGM, sino también la de otros organismos públicos productores de datos geográficos oficiales como es el caso del Instituto de Estadística y Censos y Ministerio de Agricultura entre otros. De esta manera todos esos organismos que disponían de geoportal aportaron información para apoyar la contingencia del 2016.

\section{Antecedentes}

Dentro del entorno de la geografía física, el Ecuador es un país que se ubica en una zona de contacto entre las placas continental y oceánica con una alta peligrosidad 
sísmica. La zona costera del país es en la que se han producido fuertes terremotos como el sucedido el 16 de abril de 2016, de magnitud 7.8 en la escala de Richter. El evento natural suscitado provocó graves daños en alrededor de 74 poblados con un área urbana de 22,000 hectáreas, según información del Instituto Geofísico de la Escuela Politécnica Nacional (IGP), este sismo es el de mayor magnitud y sufrimiento (Altamirano, 2017) en las últimas tres décadas en Ecuador, con un saldo de pérdidas humanas de 650 personas fallecidas.

El sismo tuvo su epicentro frente a Muisne (provincia de Manabí), a unos 170 kilómetros de la capital, Quito y se sintió en todo el país. El hipocentro se produjo en el océano Pacífico a una profundidad de 20 kilómetros. Más de 2,000 réplicas, algunas de una magnitud de hasta 6.1 grados, se presentaron desde entonces. Se trata de uno de los terremotos más dañinos que ha sufrido América Latina en la última década, después de que en 2007 golpeó a Perú (casi 600 muertos) y en 2010 a Chile (más de 150 fallecidos), sin contar la catástrofe de Haití de ese mismo año, que ocasionó más de 300,000 muertos (IGP, 2016).

Ante la emergencia suscitada, se presentó la necesidad de información para la toma de decisiones. En esta ocasión las fotografías sirvieron como insumo fundamental para la identificación de edificaciones destruidas y/o afectadas por el terremoto. Este tipo de material tiene ventajas muy conocidas en relación a estudios relacionados con la multitemporalidad de fenómenos (crecimiento/decrecimiento de zonas vegetales, modificaciones del terreno producidas por fenómenos geológicas, movimientos urbanos, etc.) (Frutos, 1976). En este sentido, el caso que nos ocupa ha servido para visualizar y cuantificar el antes y el después en las construcciones civiles y viviendas afectadas (Dureau, 1992). Este tipo de análisis multitemporales ha servido también para evaluar las consecuencias del sismo ocurrido en la zona costera del Ecuador en el año 2016.

\section{Área de estudio}

El área del presente estudio se sitúa en la zona correspondiente a las provincias de Esmeraldas (sector sur de la provincia), Manabí y Los Ríos. Esta zona se caracteriza por tener relieves que no sobrepasan los $800 \mathrm{~m}$ de altura y presenta pendientes moderadas en general, una importante presencia de cultivos y pastos, alta biodiversidad, población multiétnica y una economía basada en actividades agropecuarias, pesqueras y turísticas que constituyen la base del ingreso. Regionalmente, Pourrut (1995) clasifica a esta zona entre un clima megatérmico seco a megatérmico húmedo y está influenciada por las corrientes cálida de El Niño, durante el invierno (diciembre a mayo) y por la fría de Humboldt en el verano (junio a diciembre). La temperatura promedio se puede situar en los $25^{\circ} \mathrm{C}$ y la precipitación mensual promedio en $100 \mathrm{~mm}$. 
En el aspecto humano, se observa una dinámica de crecimiento poblacional bastante acelerada. Así, de los 600,000 habitantes que se contaban en 1950 (CAD, 1974), la población de la región en la actualidad se ha multiplicado por cuatro y aunque la tasa de crecimiento promedio ha disminuido a un $2 \%$, todavía es alta, lo que espacialmente se ha traducido en la presencia de una densa red de centros poblados. Existen poblacionales importantes como Portoviejo, centro administrativo, capital de la provincia de Manabí (223,000 habitantes), Manta, ciudad puerto comercial y motor económico de la provincia (217,000 habitantes), Babahoyo (90,000 habitantes), ciudad capital de la provincia de Los Ríos, Pedernales, ciudad dedicada a servicios turísticos (47,000 habitantes), al igual que Bahía de Caráquez (20,000 habitantes), Muisne (15,000 habitantes), constituyen las principales ciudades de la región afectada.

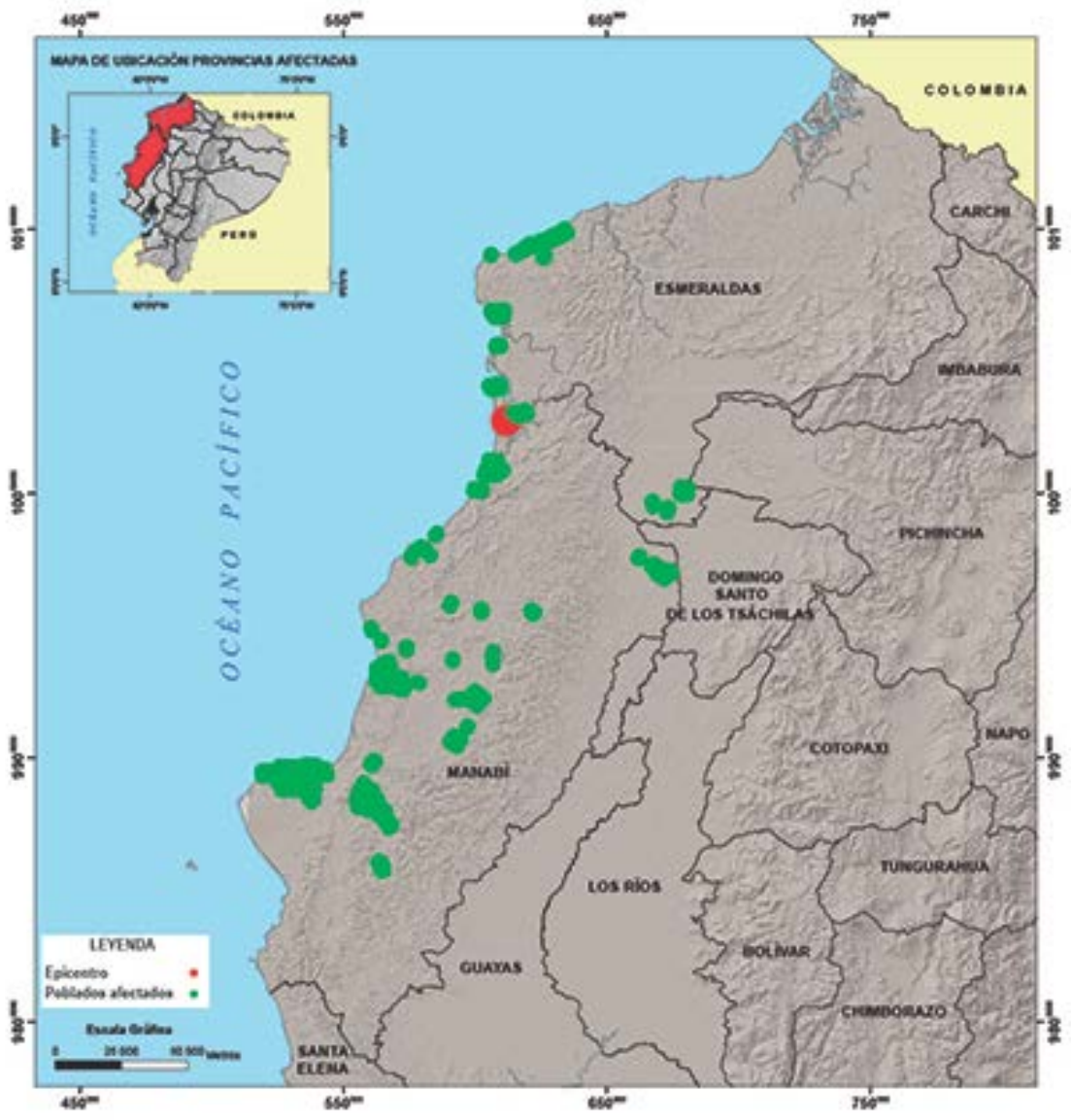

Figura 1. Mapa de ubicación de la zona afectada y las poblaciones. 


\section{Objetivo del IGM ante la contingencia}

El objetivo prioritario fue poner a disposición pública a través del Geoportal institucional toda la información de pronta respuesta generada por el IGM. A esta información no solo tendrían acceso las instituciones estatales sino también el público en general. A este respecto se puso mucho énfasis en que el diseño de la interfaz del geoportal facilitara el acceso a la información.

\section{Método de trabajo}

Para el cumplimiento de los objetivos planteados se organizó un plan de acción compuesto de cuatro fases:

- Toma de fotografía aérea mediante sensores aerotransportados

- Restitución aerofotogramétrica y fotointerpretación de edificaciones afectadas

- Elaboración de cartografía de pronta respuesta

- Publicación de la información a través del geoportal institucional.

\section{Aplicación del plan de acción en el caso de estudio}

La información base, es la de fotografía aérea a escala 1:5.000 tomada al siguiente día de la ocurrencia del terremoto, es decir el 18 de abril. La cobertura total fue de 63,000 ha, correspondiendo de éstas un 35\% a zonas de población aglomeradas o áreas urbanas que constituían los lugares donde el sismo causó los más graves daños.

También, a partir de:

- Fotografías rectificadas de los períodos 2011-2015 y 2016, utilizando métodos aerofotogramétricos y fotointerpretación,

- Información del Código de Arquitectura y Urbanismo

- Mapas temáticos del Instituto Espacial Ecuatoriano (IEE) y del Instituto Nacional de Estadísticas y Censos (INEC)

Se generaron, para cada centro poblado, los siguientes productos que por su proceso de obtención y análisis fueron denominados como "información de pronta respuesta" y que empezaron a estar disponibles para las instituciones públicas y usuarios en general a los tres días de sucedido el evento (Figura 2):

- Cartografía de los tejidos urbanos hasta el nivel de edificación

- Edificaciones totales

- Edificaciones destruidas

- Edificaciones afectadas 


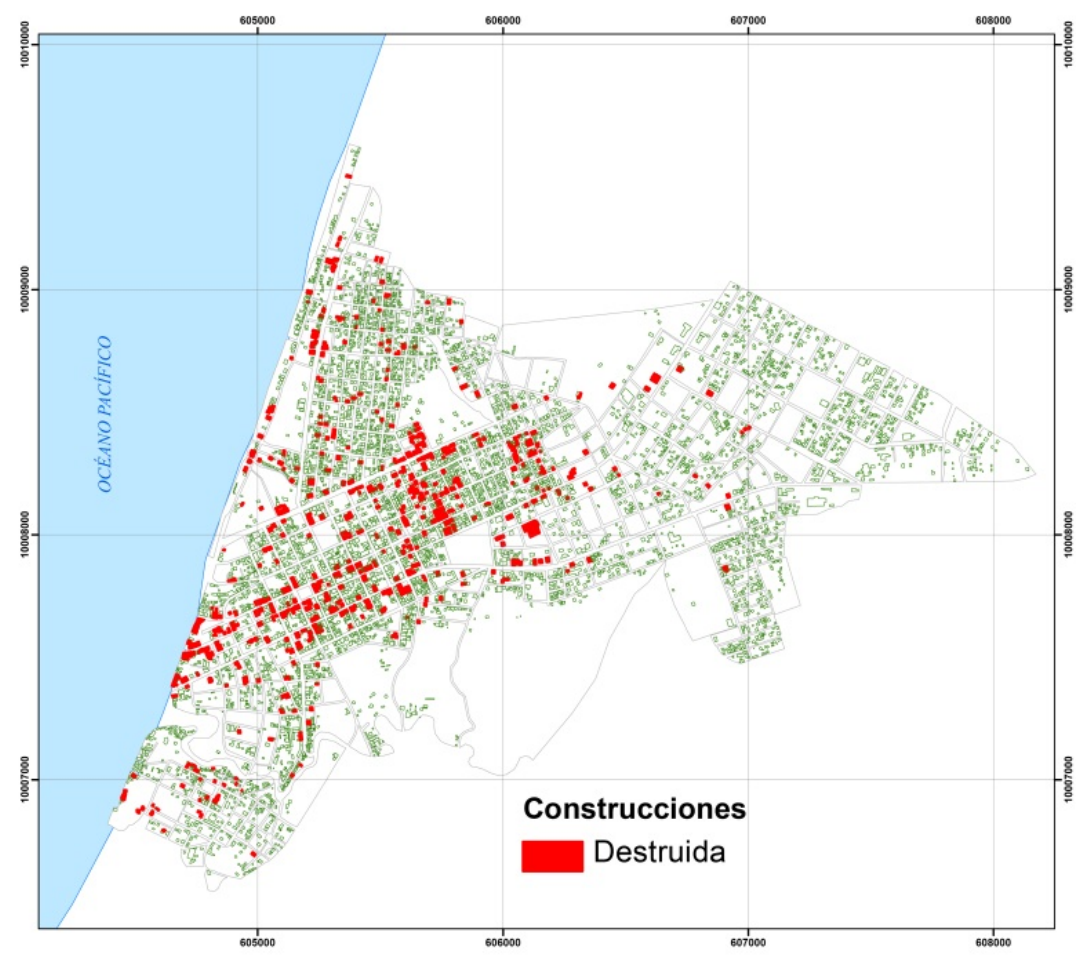

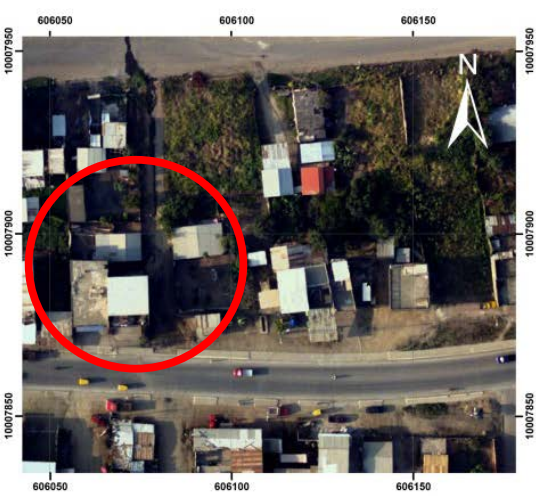

ORTOFOTO PEDERNALES ANTES DEL SISMO DEL 16 DE ABRIL DEL 2016

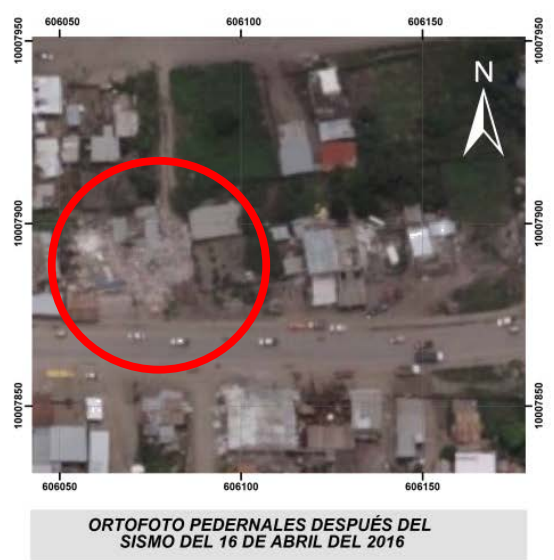

Figura 2. Ejemplo de identificación y representación de las edificaciones afectadas y/o destruidas. 
- Manzanas urbanas analizadas

- Manzanas con edificaciones destruidas y/o afectadas

- Población (en las edificaciones, obtenidas del INEC)

- Estimación del número de habitantes afectados.

Con esta información se generaron 70 publicaciones temáticas de las diferentes localidades afectadas, documento denominado: "Estimación provisional de edificaciones destruidas y afectadas”, esta estimación se registró como el porcentaje de edificaciones afectadas o destruidas sobre el total de edificaciones contabilizadas por "manzana" como unidad espacial, la facilidad de los sistemas de información geográfica y las normas preestablecidas permitió que la información generada se ponga fácil y rápidamente a disposición de los usuarios de geoinformación por medio del Geoportal institucional. El aporte de este trabajo se evidenció con la interacción y las descargas de la información de los usuarios, que principalmente fueron de entidades que participaron en la mitigación del evento, el uso de información oficial para atender la emergencia fue lo novedoso del proceso que inició con la toma de fotografía y su comparación con fotografía de años pasados que reposa en los archivos del IGM.

Los mapas que representan la estimación provisional de edificaciones destruidas y afectadas fueron generados a partir de la idea de la cartografía colaborativa de OpenStreetMap (OSM) que se especializa en dar soporte en circunstancias de desastres naturales, pretende construir una base de datos geográficos de todo el mundo. Este proyecto se califica comúnmente como libre, abierto y colaborativo (Ménard, 2010).

Paralelamente, se analizó información de variables relacionadas con las restricciones y ventajas del medio urbano para realizar tres propuestas de posibles ubicaciones de albergues y viviendas provisionales para la población damnificada. Para ello se utilizaron los siguientes recursos:

- Plano manzanero del centro poblado

- Modelo Digital del Terreno (DTM)

- Cartografía de multiamenazas (amenazas naturales)

- Cartografía de usos del suelo

- Cartografía geomorfológica

- Análisis de vialidad

- Mapa de amenazas naturales

- Documentos de factibilidad de servicios básicos y complementarios

- Seguridad ciudadana (Unidades de Policía Comunitaria) 
Esta información se incluyó en el atlas Propuestas de áreas para viviendas provisionales (Figura 3), que fue colocado en el Geoportal en diferentes tipos de formatos y además se entregó impreso al Ministerio de Urbanidad y Vivienda, institución encargada de construir los albergues en las zonas afectadas. Los datos de acceso y descarga de información se presentan más adelante.
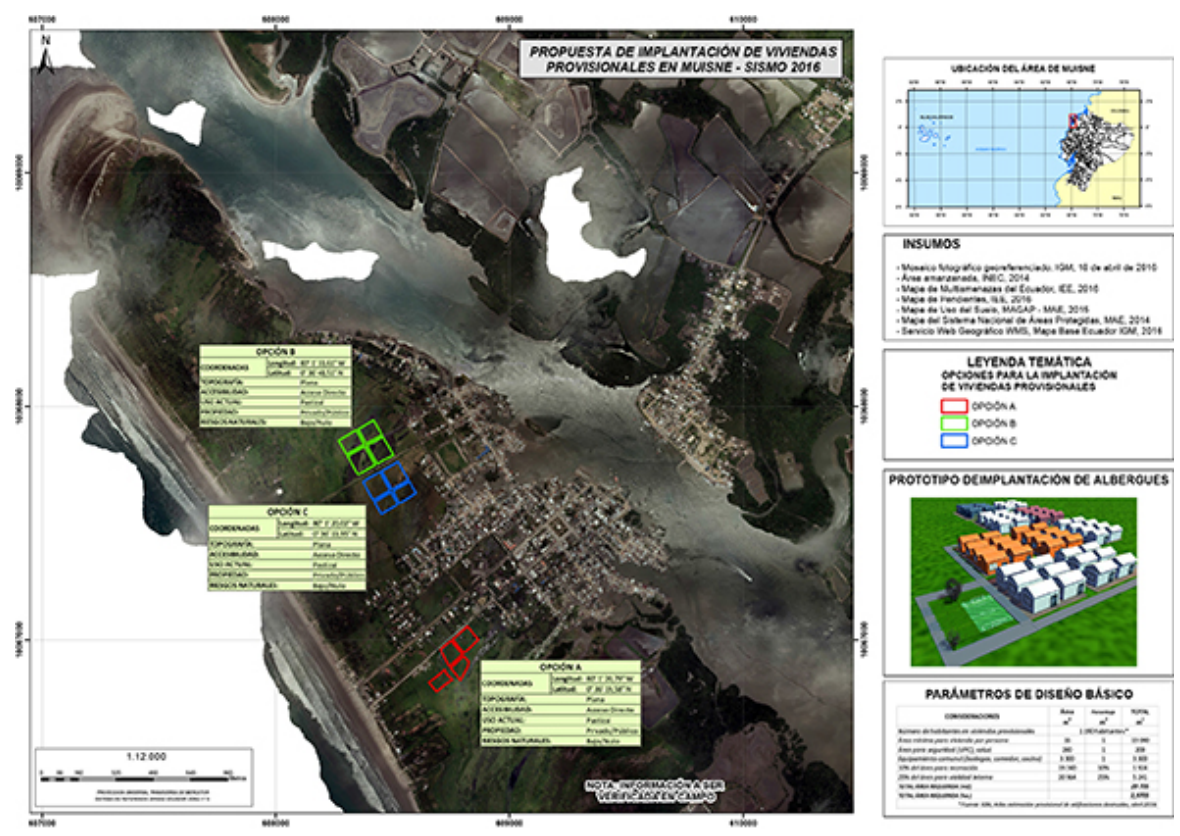

Figura 3. Ejemplo de identificación de áreas para posible ubicación de albergues.

\section{El Geoportal del Instituto Geográfico Militar}

La funcionalidad del Geoportal institucional durante la emergencia ocurrida a partir del 16 de abril del 2016 fue trascendental. La actualización y distribución de la información fue concebida rápidamente y con altos niveles de confianza, la finalidad fue entregar al usuario información clave en la toma de decisiones posterior al desastre y de esta manera permitir que cada institución pública, dentro de su competencia, realice sus funciones con mayor efectividad, basadas en datos oficiales de la entidad generadora de geoinformación.

\section{El proceso requerido para la elaboración y publicación de la información cartográfica del sismo del 16 de abril de 2016}

El proceso que se sigue para la publicación de la información geográfica es minucioso, y aunque la información es de pronta respuesta, se requiere cumplir algunas 
tareas de control básico, como por ejemplo el chequeo topológico, configuración de la base de datos básica y una adecuada representación temática de la información. La Figura 4 representa el plan de acción que se configuró para la atención a la emergencia del cual el proceso de elaboración y publicación de la información cartográfica que se siguió inmediatamente después del sismo fueron los puntos principales a considerar (IDE-IGM, 2016).

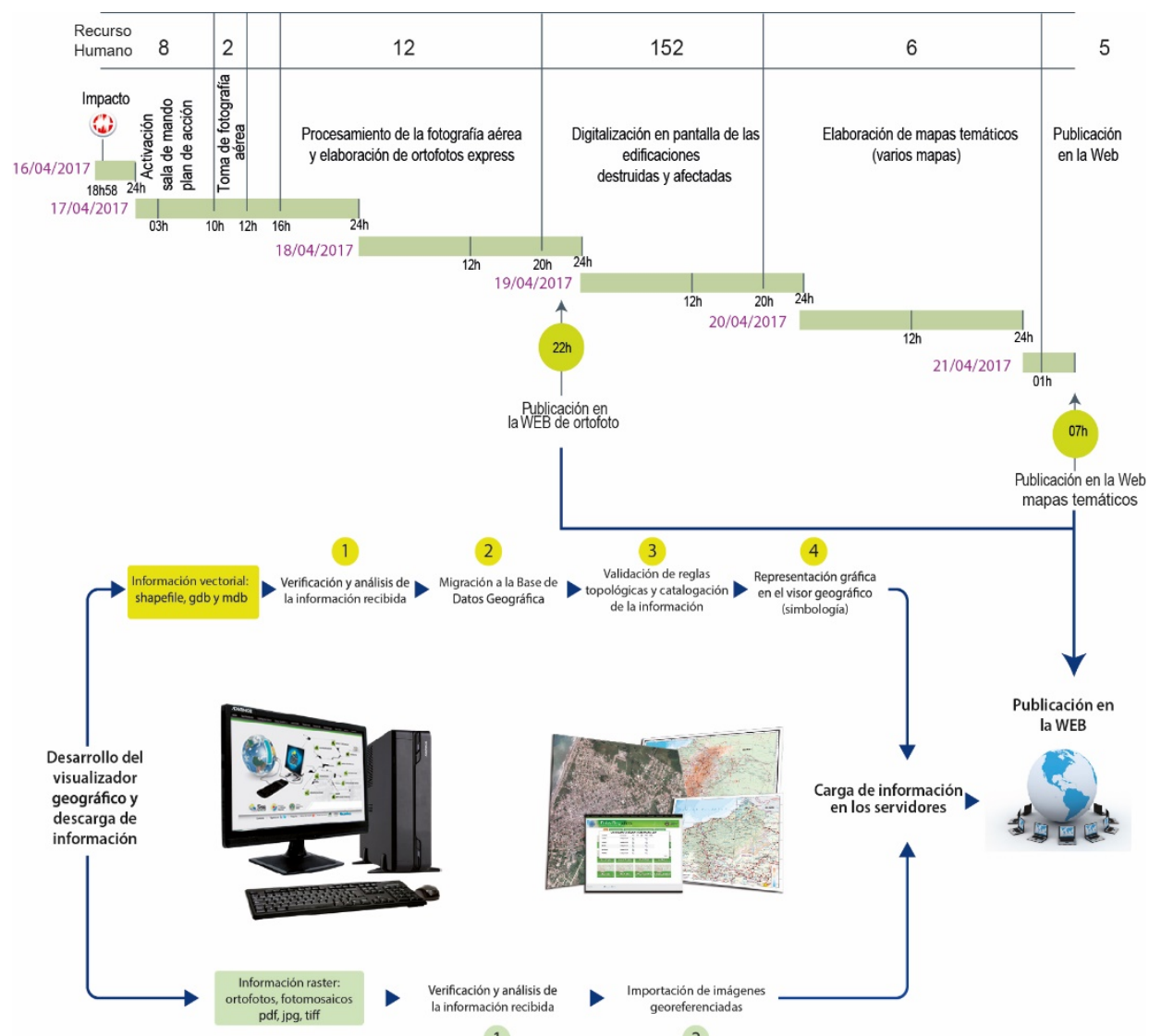

Nota: Los pasos 2 y 3 de la información vectorial están correlacionados, ya que contienen restricciones especificas de campos completamente llenos y topología.

\section{Tiempo total transcurrido : 4 dias}

Figura 4. Proceso de elaboración y publicación de información cartográfica de pronta respuesta en la Web.

Para facilitar el acceso a la información tanto de las instituciones públicas como del público en general, se creó un visor especial para la descarga de la información 
con acceso directo y muy visible desde la página principal del Geoportal del IGM (<http://www.geoportaligm.gob.ec/portal/index.php/sismo-2016/>). Para facilitar la descarga de información se organizaron tres menús: cartografía básica, temática y fotografía aérea (antes y después del sismo) (Figura 5).

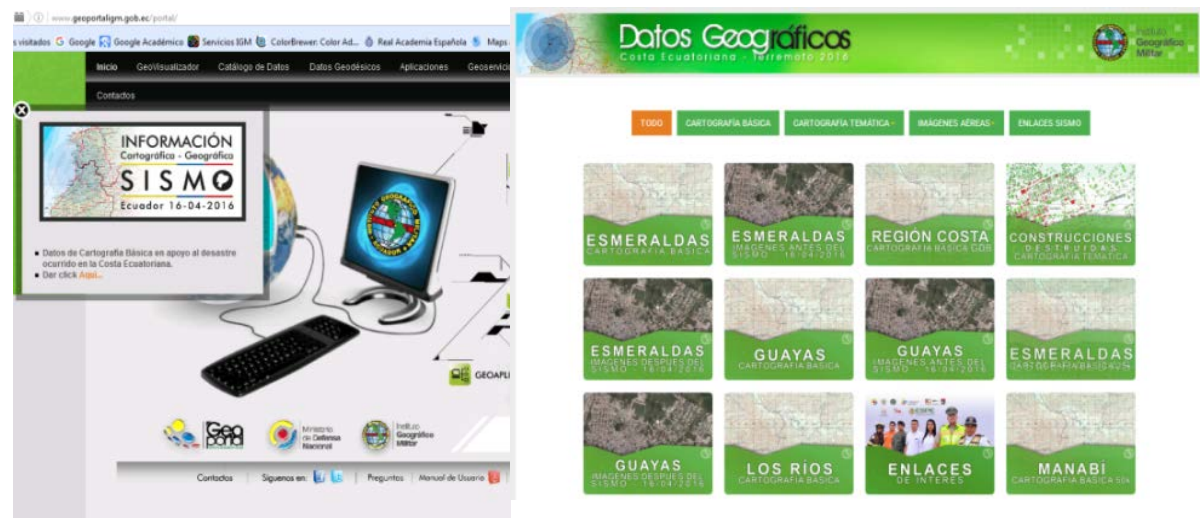

Figura 5. Portada de la pantalla de inicio del Geoportal del IGM, 2016.

La información publicada y disponible en el Geoportal del IGM, en el visor "Terremoto 2016" se encuentra en varios formatos: jpg, pdf, tiff y shapefile que se despliega en sistemas de información geográfica. Dicha información corresponde a cartografía básica a diferentes escalas y mapas provinciales; cartografía temática a escala 1:25.000 de geomorfología, suelos, uso del suelo, etc. y también los Atlas de "Propuestas de albergues provisionales" y de "Estimación de construcciones destruidas"; fotografías aéreas, fotomosaicos y ortofotos (antes y después del evento).

Es importante destacar la usabilidad del Geoportal, lo que permitió manejar una terminología fácil sin tecnicismos que compliquen entender el tipo de información que se disponía, además se contó con gran cantidad de contenidos gráficos (diseños y logos) que diferenciaron los contenidos. La navegación dentro del ambiente del Geoportal (visor terremoto) es muy simple y permite recorrer ágilmente los contenidos con un buscador adaptado a todos los niveles de información geográfica, posee también una adecuada simbología gráfica en función del tipo de mapa que se representó el los atlas impresos; todo esto permitió evidenciar el interés en facilitar la información a toda la población con tiempos de respuesta muy diferentes al proceso normal de publicación de la cartografía oficial, la que requiere de controles más rigurosos.

La línea del tiempo de la Figura 6, representa la información cartográfica publicada durante el Estado de Emergencia del sismo, donde se destaca que se han car- 


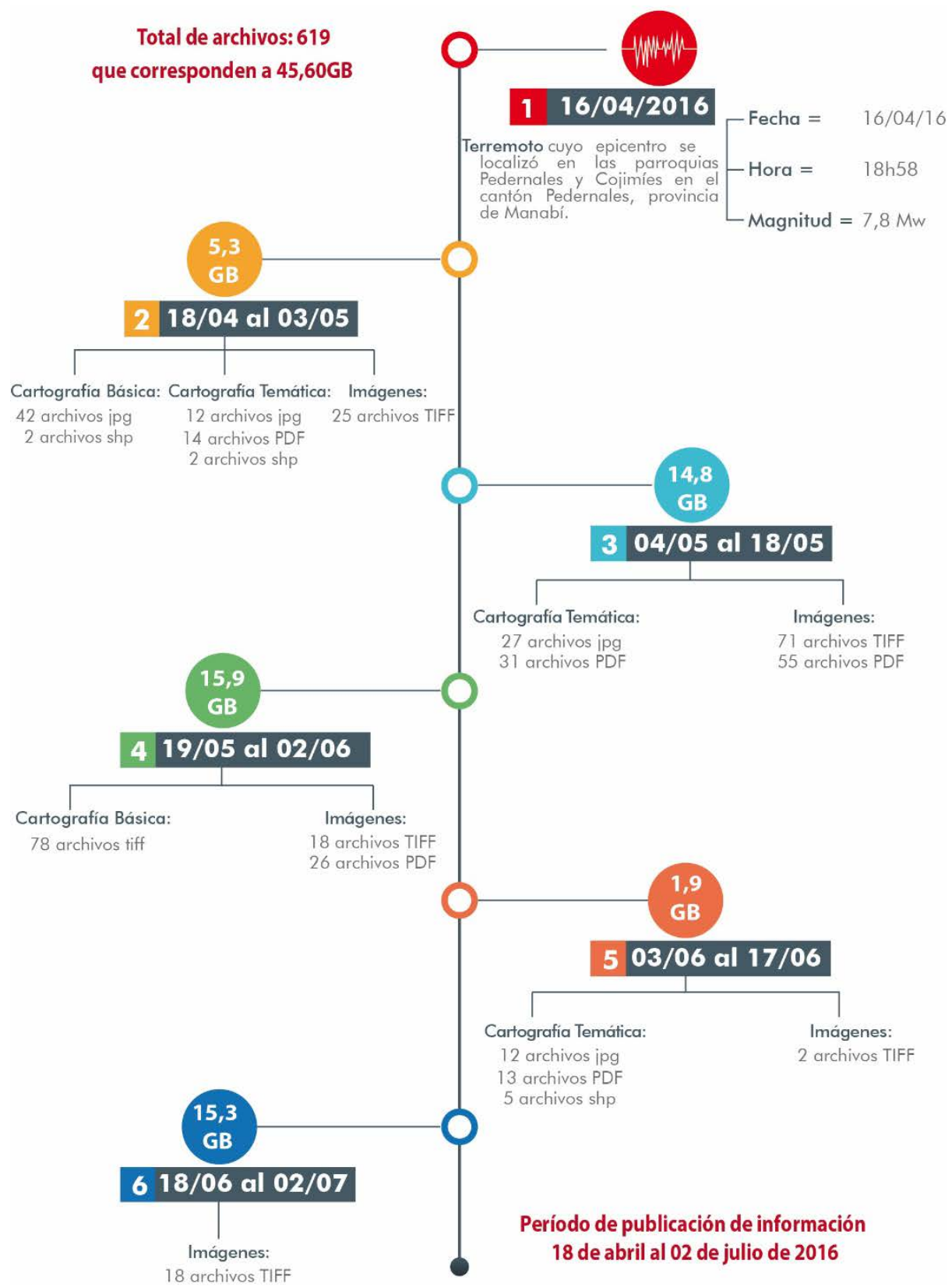

Figura 6. Línea del tiempo de la información cartográfica publicada y liberada durante el Estado de Emergencia del sismo del 16 de abril de 2016. 
gado un total de 619 archivos que corresponden a 45.6 GB de información totalmente libre y disponible para la descarga y consulta pública, además el gráfico presenta los tiempos a medida que se cargaron los productos al Geoportal del IGM lo que permitió la trasmisión inmediata de la información geográfica en todo el territorio nacional, sin este instrumento la distribución habría sido muy difícil de realizar.

Se registró un total de 75.082 descargas desde abril hasta julio de 2016; de este valor, 10,414 (28\%) corresponden a archivos de cartografía básica, 8,265 (22\%) son de temática, 12,334 (33\%) son imágenes después del sismo y 6,528 (17\%) son imágenes de luego del sismo, tal como se puede observar en la Figura 7.

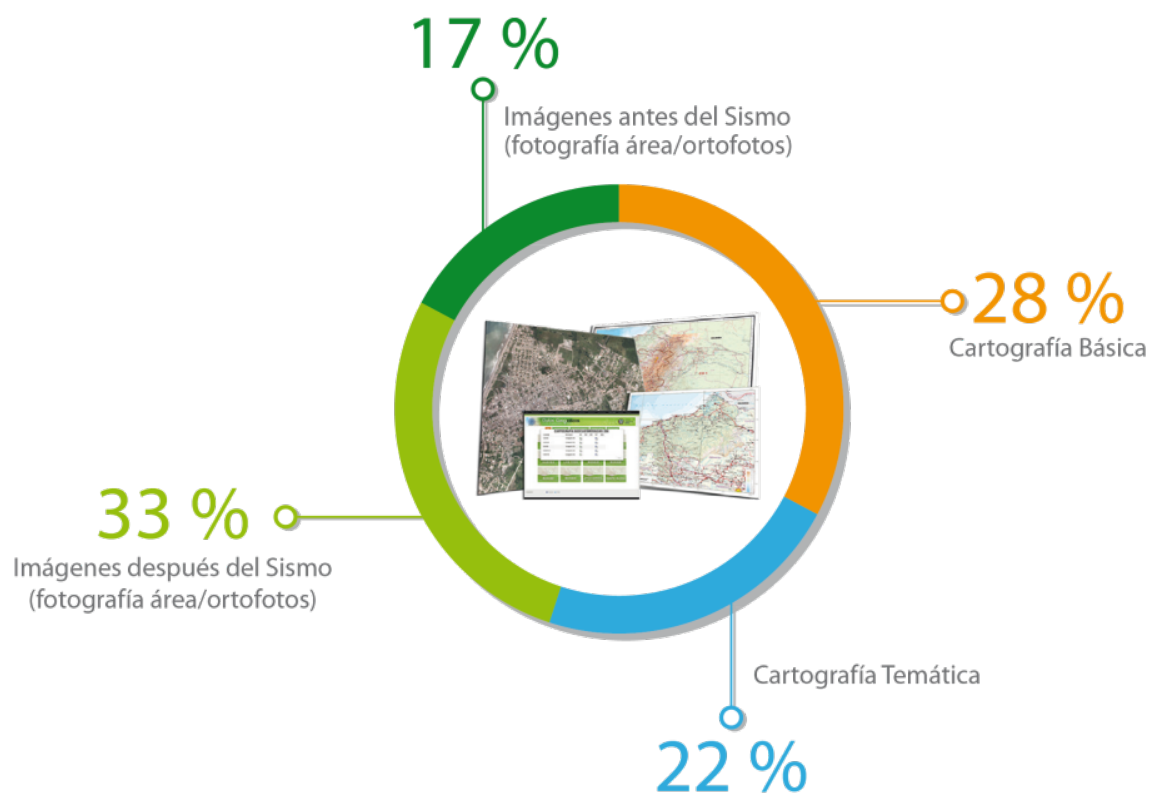

Figura 7. Descargas totales de archivos desde el 16 de abril hasta el 31 de julio de 2016.

Los gráficos estadísticos presentan el número de descargas en tres cortes de fechas de la cartografía básica, temática e imágenes. Dentro de la categoría cartografía básica, los archivos más descargados son: los shape file a escalas 1:5.000 y 1:25.000 (Figura 8).

En cuanto a la categoría cartografía temática, los archivos más requeridos fueron los mapas de ubicación de los estudios de propuestas de albergues provisionales y los atlas de estimación de construcciones destruidas y afectadas. La Figura 9 muestra el número de descargas por fechas. 


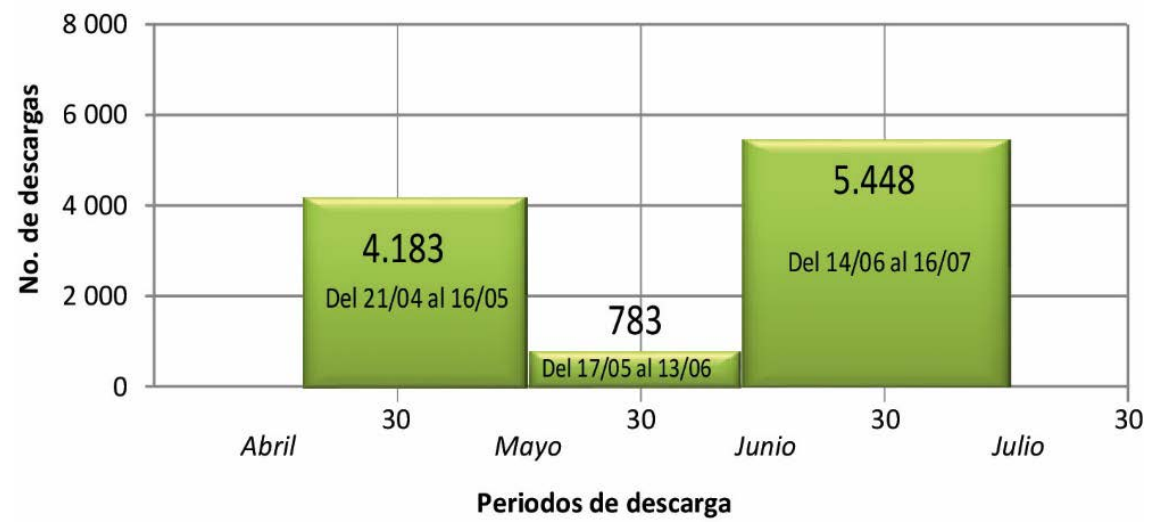

Figura 8. Descargas de cartografía básica desde el 16 de abril hasta el 31 de julio de 2016.

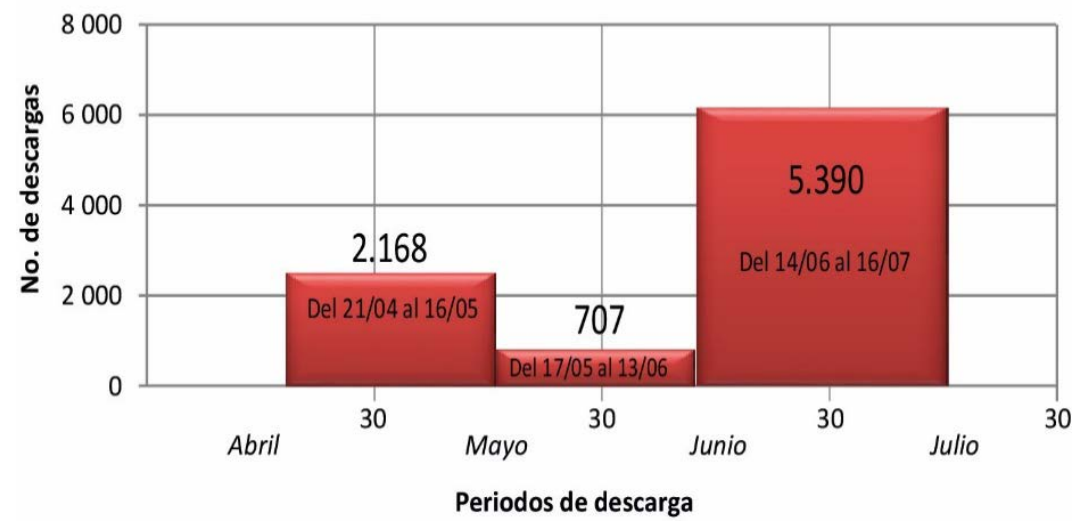

Figura 9. Descargas de cartografía temática desde el 16 de abril hasta el 31 de julio de 2016.

Los archivos de imágenes, fotografía aérea, ortofotos y fotomosaicos han sido los más descargados. Entre las imágenes que lideran la lista de descargas están Manta, Muisne, Pedernales y Portoviejo (zonas de mayor afectación por el sismo). Los gráficos que se presentan a continuación representan el número de descargas por fechas y por tipo (imágenes antes y después del sismo), el 35\% de descargas corresponden a imágenes tomadas antes del sismo, y el 65\% a imágenes tomadas después del sismo (Figura10). 
Finalmente, es importante destacar que, a nivel nacional, el Geoportal registra visitas de todas las provincias y también desde el exterior. La información cargada en el portal fue requerida tanto por instituciones públicas como privadas, entre las que se encuentran Ministerios como el de Urbanismo y Vivienda (MIDUVI), del Ambiente Ecuatoriano (MAE), Secretaría de Gestión de Riesgos (SGR), Ministerio de Coordinación de Desarrollo Social (MCDS), de Coordinación de Seguridad (MICS), Cuerpo de Ingenieros del Ejército, Ministerio de Defensa Nacional (MIDENA), entre otras, las que dieron diferentes usos a la información generada y publicada como se puede ver en la Tabla 1.

\section{Tabla 1}

Usos y aplicaciones de la información generada después del sismo

\begin{tabular}{|c|c|}
\hline Institución & Uso y aplicación de la información \\
\hline $\begin{array}{l}\text { Ministerio de Desarrollo Urbano y } \\
\text { Vivienda }\end{array}$ & $\begin{array}{l}\text { Verificación de edificaciones destruidas y/o afectadas } \\
\text { en campo, por la escala de trabajo esta información se } \\
\text { constituyó en fundamental para la validación en } \\
\text { campo y toma de decisiones }\end{array}$ \\
\hline Secretaría de Gestión de Riesgos & $\begin{array}{l}\text { Planificación de operativos de reacción inmediata y } \\
\text { tareas de reconstrucción posterior al evento }\end{array}$ \\
\hline Ministerio del Ambiente & $\begin{array}{l}\text { Determinación de áreas inundadas y afectadas por el } \\
\text { sismo }\end{array}$ \\
\hline Cuerpo de Ingenieros del Ejército & $\begin{array}{l}\text { Determinación de áreas funcionales tanto sociales } \\
\text { como físicas para la ubicación de albergues } \\
\text { temporales }\end{array}$ \\
\hline $\begin{array}{l}\text { Ministerio Coordinador de } \\
\text { Seguridad Social }\end{array}$ & $\begin{array}{l}\text { Planificación de ayuda social y la implementación de } \\
\text { programas sociales }\end{array}$ \\
\hline INEC & $\begin{array}{l}\text { Planificación inmediata para el levantamiento de } \\
\text { información social estadística }\end{array}$ \\
\hline Ministerio de Defensa & $\begin{array}{l}\text { Planificación de los operativos de socorro y seguridad } \\
\text { por parte del personal de Fuerzas Armadas }\end{array}$ \\
\hline Policía Nacional & Planificación de operativos de seguridad ciudadana \\
\hline Organismos de Planificación Local & $\begin{array}{l}\text { Planificación de la reconstrucción de servicios } \\
\text { básicos y complementarios }\end{array}$ \\
\hline $\begin{array}{l}\text { Ministerio de Transporte y Obras } \\
\text { Públicas }\end{array}$ & $\begin{array}{l}\text { Planificación de reconstrucción de infraestructura } \\
\text { terrestre }\end{array}$ \\
\hline Empresas de Seguros & Identificación de grado de afectación a edificaciones \\
\hline
\end{tabular}

Fuente: IDE-IGM, 2016. 


\section{Descarga de Imágenes tomadas}

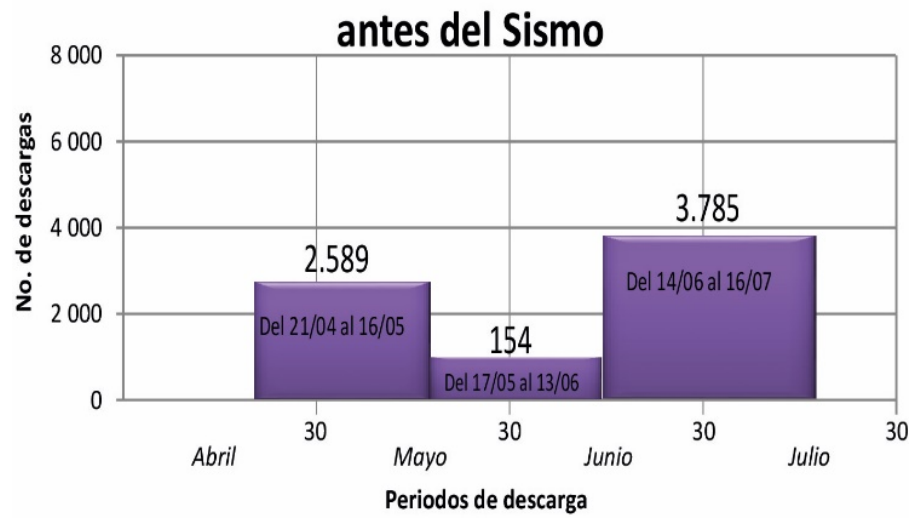

\section{Descarga de Imágenes tomadas}

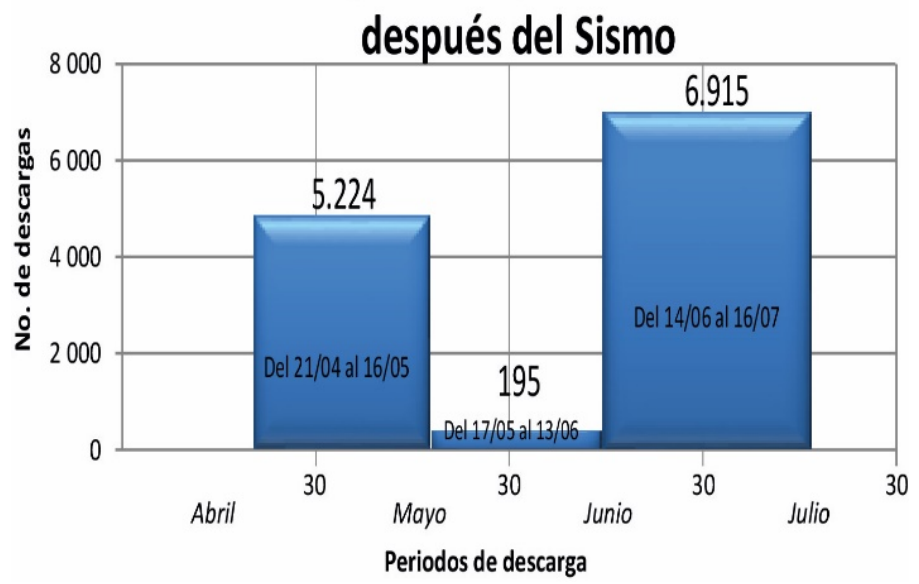

Figura 10. Descargas de imágenes tomadas antes y después del sismo.

\section{Conclusiones}

Las acciones desplegadas en el ámbito geográfico-cartográfico y de comunicaciones a partir de la emergencia presentada el 16 de abril de 2016, han demostrado la gran utilidad que prestan tanto la información de pronta respuesta como las tecnologías de información, a través de los Geoportales, para enfrentar a los riesgos naturales.

La generación de información de pronta respuesta está vincula directamente con el factor tiempo, y su disponibilidad está ligada a las facilidades que las IDE en este caso brindaron para poner al alcance de todos la información. 
El acceso a información geográfica por medios tecnológicos evidenció un importante ahorro de recursos económicos y de tiempos de respuesta para atender a la población damnificada, esto fue evidente en todas las evaluaciones posteriores al evento natural donde diferentes instituciones del Estado ecuatoriano realizaron el reconocimiento a la pertinencia y disponibilidad de la información proporcionada por el IGM.

La dinámica que presentan las IDE en lo referente al intercambio y disponibilidad de información es de suma utilidad al momento de atender situaciones de emergencia, en donde la información geográfica es básica para la toma de decisiones en especial de las autoridades competentes en el tema.

Después del desastre, se han hecho evidentes los requerimientos de contar con geoinformación tales como cartografía básica a escalas grandes y medianas, así como de fotografías aéreas insumos básicos para atender las actividades realizadas después de producido el evento natural. Esta situación se corrobora por la cantidad de usuarios que visitan y realizan descargas de geoinformación de manera mensual en el Geoportal Institucional (sin considerar contingencias catastróficas), que en promedio es de 2,000 descargas, mientras que el promedio en tiempos de emergencia creció a nueve veces más que el valor antes mencionado.

La necesidad de disponer en el menor tiempo posible de información específica actualizada relacionada directamente con el riesgo, se pone de manifiesto por la necesidad de generar una cartografía de pronta respuesta con la cual planificar, formular y ejecutar programas de rehabilitación de ayuda social, vivienda, educación, salud, seguridad, dotación de servicios básicos, entre otros.

Varias fueron las lecciones aprendidas en el proceso de generación y publicación de la información generada, siendo una de las principales para mejorar la usabilidad la de incorporar en el futuro un buscador que facilite la consulta de los datos existentes en el visor creado, así como también la disponibilidad de abrir en chat en tiempo real para conocer las necesidades de los usuarios para mejorar en tiempo y forma la entrega de geoinformación a través del geoportal institucional.

\section{Agradecimientos}

El presente trabajo fue realizado gracias a la colaboración del área de Infraestructura de Datos Espaciales del Instituto Geográfico Militar, Ecuador (IGM) quienes facilitaron los datos de descargas y accesos, la base de su filosofía de trabajo es el libre acceso a los datos y su correspondiente descarga.

Nuestro más sincero reconocimiento a todos los técnicos, ingenieros y autoridades del IGM que participaron activa y voluntariamente en el relevamiento de la información base, pensando en la necesidad del país a fin de contar con información de primera mano y fidedigna para la gestión de mitigación del evento natural del 16 de abril de 2016. 


\section{Bibliografía}

Aguilar, A. y Liliana, R. (2017). Evolución del glaciar del volcán Nevado del Huila a través del tratamiento de imágenes satelitales (1987-2016).

Altamirano, C.A.T. (2017). "Evaluación cuantitativa del sufrimiento mediante la escala de afecto positivo y negativo (PANAS) en las víctimas del terremoto de Pedernales-Ecuador 2016”, Práctica Familiar Rural, vol. 1. $<$ http://saludrural.org/index.php/saludrural/article/view/167/VER\%20EN\%20LI NEA $>$ recuperado el 4 de abril de 2017.

Andrade Santamaría, A.A. y Molina Bustamante, C.S. (2016). "Estudio del estado del arte de las tecnologías de percepción remota en el Ecuador”, BS thesis. Quito, Universidad de las Américas. <http://dspace.udla.edu.ec/bitstream/ 33000/6050/1/UDLA-EC-TIRT-2016-21.pdf> recuperado el 4 de abril de 2017.

Buzai, G., y Ruiz, E. (2014). "Geotecnósfera. Tecnologías de la información geográfica en el contexto global del sistema mundo”, Anekumene, vol. 1, núm. 4, pp. 88-106.

Carrasco, C., (2017). "Entrevista Jefe del Departamento de Investigación y Desarrollo del IGM, Chile", Diálogo, Revista Militar Digital. <https://dialogoamericas.com/es/articles/chilean-army-creates-system-mitigate-natural-disasterdamage > recuperado el 4 de abril de 2017.

Dureau, F. (1992). El método de muestreo de áreas con base en imágenes de satélite, Centro de Estudios de Desarrollo Económico, Universidad de los Andes, Bogotá D.C., Colombia, pp. 6-7.

Frutos, L.M. (1976). "La aplicación de la fotografía aérea al estudio de la evolución del paisaje: el modelo de Berdún”, Cuadernos de Investigación. Geografía e Historia, Ciudad Universitaria de Logroño, tomo II, pp. 3-8.

IDE-IGM (2016). "Presentación del proyecto: uso de la IDE-IGM para generar estudios de pronta respuesta, caso de estudio: Sismo del 16 de abril de 2016”, Quito, Ecuador.

Instituto Geofísico de la Escuela Politécnica Nacional (IGP). (2016). Sismos 2016, Quito, Ecuador.

Ménard, S. (2010). El uso de OpenStreetMap en el contexto humanitario, pp. 33-35. Monet, A. (2014). IDE Chile y la gestión de riesgos y emergencias, Secretaría Ejecutiva SNIT IDE-Chile, Ministerio de Bienes Nacionales, Oficina Nacional de Emergencias.

Olaya, V. (2014). "Sistemas de Información Geográfica”, <http://volaya.github. io/libro-sig/index.html> recuperado el 4 de abril de 2017.

Pourrut, P. et al. (1995). El agua en el Ecuador: clima, precipitaciones, escorrentía, Quito, Ecuador. 
Rodríguez-Pascual, A.R.; Power, P.A.; Jiménez, J.A., y Maganto, A.S. (2006). La Infraestructura de Datos Espaciales de España (IDEE): un proyecto colectivo y globalizado. Avances en las infraestructuras de datos espaciales, pp. 15-26.

Sánchez-Maganto, A.; Bernabé-Poveda, M.A.; Rodríguez Pascual, A.F. (2012). “Componentes de una IDE”, en Bernabé-Poveda, M.A., y López-Vázquez, C.M., Fundamentos de las Infraestructuras de Datos Espaciales, Madrid, UPM-Press, Serie Científica, pp. 31-40.

Tait, M.G. (2005). "Implementing geoportals: applications of distributed GIS", Computers, Environment and Urban Sistemas, vol. 29, núm. 1, pp. 33-47. 